\title{
A comparative life cycle assessment of process water treatment technologies at the Secunda industrial complex, South Africa
}

\author{
C Ras* and $\mathrm{H}$ von Blottnitz \\ Environmental and Process Systems Engineering Research Group, Department of Chemical Engineering, \\ University of Cape Town, Cape Town, South Africa
}

\begin{abstract}
The increasingly poor quality of South Africa's natural water sources requires industries and power stations to treat raw water extensively prior to industrial use in, for example, boilers. Two different raw water desalination technologies, an existing ion exchange plant and a proposed reverse osmosis intervention, are compared by life cycle assessment for the production of $1 \mathrm{M} \ell$ of boiler feed water, in the context of the Secunda industrial complex situated in Mpumalanga, South Africa. The proposed reverse osmosis option would perform $22 \%$ worse for global warming potential, which relates to the use of coal-derived electricity, but would reduce burdens of the ion exchange option on human toxicity and freshwater aquatic ecotoxicity due to the use of an aluminium sulphate coagulant. Significantly, the assessment predicts the reverse osmosis option to effect a $78 \%$ overall reduction in storage of problematic salts, from $599 \mathrm{~kg} / \mathrm{M} \ell$ to $133 \mathrm{~kg} / \mathrm{M} \ell$. Notwithstanding the fact that the power generated within the complex and used by the RO process is associated with a high salts burden (mine water is desalinated at the power station), it was found that the reverse osmosis intervention would incur a lower salts footprint than the IX/S technology and would not shift salts burdens.
\end{abstract}

Keywords: industrial water systems, life cycle assessment, desalination, technology comparison, ion exchange, reverse osmosis

\section{Introduction}

South Africa's aspirations for economic growth rely to a great extent on expansion of industrial manufacturing. Several large industrial hubs have been established to add value to extracted mineral resources by means of chemical or metallurgical transformations into intermediate or final products. These activities however lead to dissipative losses of vast volumes of freshwater for cooling purposes, which give rise to sustainability concerns, given that the catchment areas in which many of these industries were built are relatively water scarce (Rogers et al., 2008). In response to these water constraints, some industrial facilities were historically designed to operate on a basis of Zero Liquid Effluent, yet they are marked by water and salt balance problems (Ras, 2011). Problems related to this approach have been identified in what is described as the 'Secunda industrial complex', comprising of the industrial activities at the Sasol Synthetic Fuels production site near Secunda, Eskom's Tutuka power station near Standerton, and their associated coal mines (Rogers et al., 2008 and Ras et al., 2010a). Water balance problems result from storage capacity constraints and poor housekeeping, where streams with widely varied qualities are indiscriminately mixed and disposed of to saturated ash systems resulting in the production of poor quality ash effluent which requires treatment (Ras, 2011). The configuration of wastewater and raw water desalination units as ion exchange technologies contribute to salt balance problems. A positive feedback loop is established where treatment of salts

\footnotetext{
To whom all correspondence should be addressed.

푱 +27 216502518 ;

e-mail: corneliaras@gmail.com

Received 29 July 2011; accepted in revised form 5 July 2012
}

requires the addition of chemicals which liberate further ions into the wastewater stream.

In an attempt to address the effects of problematic salt and water balances, industries in the Secunda complex have pursued several initiatives for salt recovery and the exchange of water between industries to alleviate water balance problems. A notable water exchange is the longstanding desalination of excess saline mine water from adjacent coal mines by the Tutuka power station and by Sasol's Secunda facility (Buhrmann et al., 1999; Burger, 2004). Further potential initiatives include an exchange of low total dissolved solids (TDS) waste streams to a water-constrained gold mine for gold recovery from dormant slimes dams and the use of mine water for cooling purposes (Ras, 2011). Attempts at addressing the salts accumulation problem include the reported recovery of sodium sulphate from sodium and sulphate-rich mine water for the vanadium industry, an aborted attempt at recovering calcium and sodium carbonates (Ras et al., 2010b), and investigation into the co-disposal of saline wastewater with ash (Ras, 2011).

These efforts have typically not been explicit about the systemic nature of the problems they attempt to address. An industrial ecology-type approach, such as industrial symbiosis, has not featured strongly in these endeavours.

A recent study has applied industrial ecology to understand environmental sustainability problems relating to the accumulation of saline wastes in the Secunda complex, and to study the potential for integrated technology interventions which take multi-party engagements and effects into account (Ras et al., 2010a). Out of this assessment, a number of possible interventions were developed, drawing on The Natural Step Framework (The Natural Step, 2011) and the Waste Management Hierarchy (Ras, 2011). The preferred intervention proposed a source reduction approach to the salts problem in the complex by replacing the existing chemical-intensive ion exchange and 
softening process (IX/S) for the production of boiler feed water with a membrane-based reverse osmosis (RO) technology. This paper presents a comparative life cycle assessment of these technologies.

\section{Life cycle assessment goal and scope}

The goal of the study was to establish whether the RO system represents a better means for boiler feed water (BFW) preparation or whether it results in burden-shifting to other industries in the complex from which inputs would be drawn. The functional unit was defined as the production of $1 \mathrm{M \ell}$ of BFW from low-salinity surface raw water, to the standards specified in Table 1, by either the IX/S or RO technology.

\begin{tabular}{|c|c|c|}
\hline \multicolumn{3}{|c|}{$\begin{array}{c}\text { Table } 1 \\
\begin{array}{c}\text { Water qualities of raw water and boiler feed } \\
\text { water (Roux, 2010) }\end{array}\end{array}$} \\
\hline Component & $\begin{array}{c}\text { Raw water } \\
(\mathrm{mg} / \mathrm{l})\end{array}$ & $\begin{array}{c}\text { Boiler } \\
\text { feed water } \\
(\mathrm{mg} / \mathrm{l})\end{array}$ \\
\hline $\mathrm{Na}^{*}$ & 15.3 & $<1.5$ \\
\hline $\mathrm{Mg}^{*}$ & 11.3 & $<0.1$ \\
\hline $\mathrm{Ca}^{*}$ & 15.7 & $<0.1$ \\
\hline $\mathrm{Cl}^{*}$ & 11.7 & $<0.1$ \\
\hline $\mathrm{SO}_{4}{ }^{*}$ & 37.4 & $<2$ \\
\hline $\mathrm{Si}^{*}$ & 8.32 & $<0.5$ \\
\hline Total hardness as $\mathrm{CaCO}_{3}$ & 105.8 & 0 \\
\hline TDS & 200 & $<10$ \\
\hline
\end{tabular}

*Dissolved component

System boundaries were defined for the two systems compared in this analysis (Fig. 1). In the top part of Fig. 1 is the IX/S system, which is comprised of upfront clarification and flocculation, and a sequence of demineralisation, sodium softening and hot lime softening. Hot lime softening (HLS) employs low pressure (LP) steam and treatment chemicals to facilitate the precipitation of calcium and magnesium hardness and silica. The product is filtered by dolomite sand filters to remove floc, odour and pathogens before it is routed to Sodium Softening (NaZ) and Old Demineralisation (OD). Old Demineralisation and New Demineralisation (ND) are to produce water of the desired quality for the boilers. The primary desalination mechanism of the IX/S system is based on the adsorption of dissolved inorganic ions from the feed solution onto resin material in the units.

The mechanism for $\mathrm{NaZ}$ is the adsorption of dissolved $\mathrm{Ca}^{++}$ and $\mathrm{Mg}^{++}$ions onto a zeolite resin structure and the simultaneous release of the stoichiometric amount of $2 \mathrm{~mol}$ of $\mathrm{Na}^{+}$off the resin. ND and OD operate similarly to NaZ but the presence of both strong and weak acid cation and strong and weak base anion exchanger resins allow for the adsorption of both cations and anions, respectively, with the subsequent release of stoichiometric amounts of $\mathrm{H}^{+}$and $\mathrm{OH}^{-}$, respectively, from the resins. A ratio of $\mathrm{ND}, \mathrm{OD}$ and $\mathrm{NaZ}$ products of 0.33:0.08:1 is employed as this corresponds to the commercial operation of the units (Ras 2011).

The reverse osmosis system shown in the bottom part of Fig. 1 is comprised of a pre-treatment step, ultrafiltration, and finally reverse osmosis. Pre-treatment uses cartridge filters to protect pumps and membranes by retaining large particulate matter; chemicals are dosed to mitigate bioactivity in supply lines, prevent mineral scale formation in the RO unit and protect membranes from attack by residual free chlorine.

The ecoInvent database was used in SimaPro version 7.3 LCA software. The life cycle impact assessment (LCIA) method CML 2 baseline 2000 V2.04 was employed with the following LCIA categories employed in the study: global warming potential (GWP), acidification, eutrophication human toxicity, freshwater aquatic ecotoxicity, depletion of abiotic resources. Salinisation was reported separately at the inventory level.

\section{Life cycle inventory analysis results}

Raw water is lost to the HLS sludge and in the regeneration of ion exchange resins; hence the water recovery of the IX/S system is $96 \%$. This is demonstrated in Fig. 2.

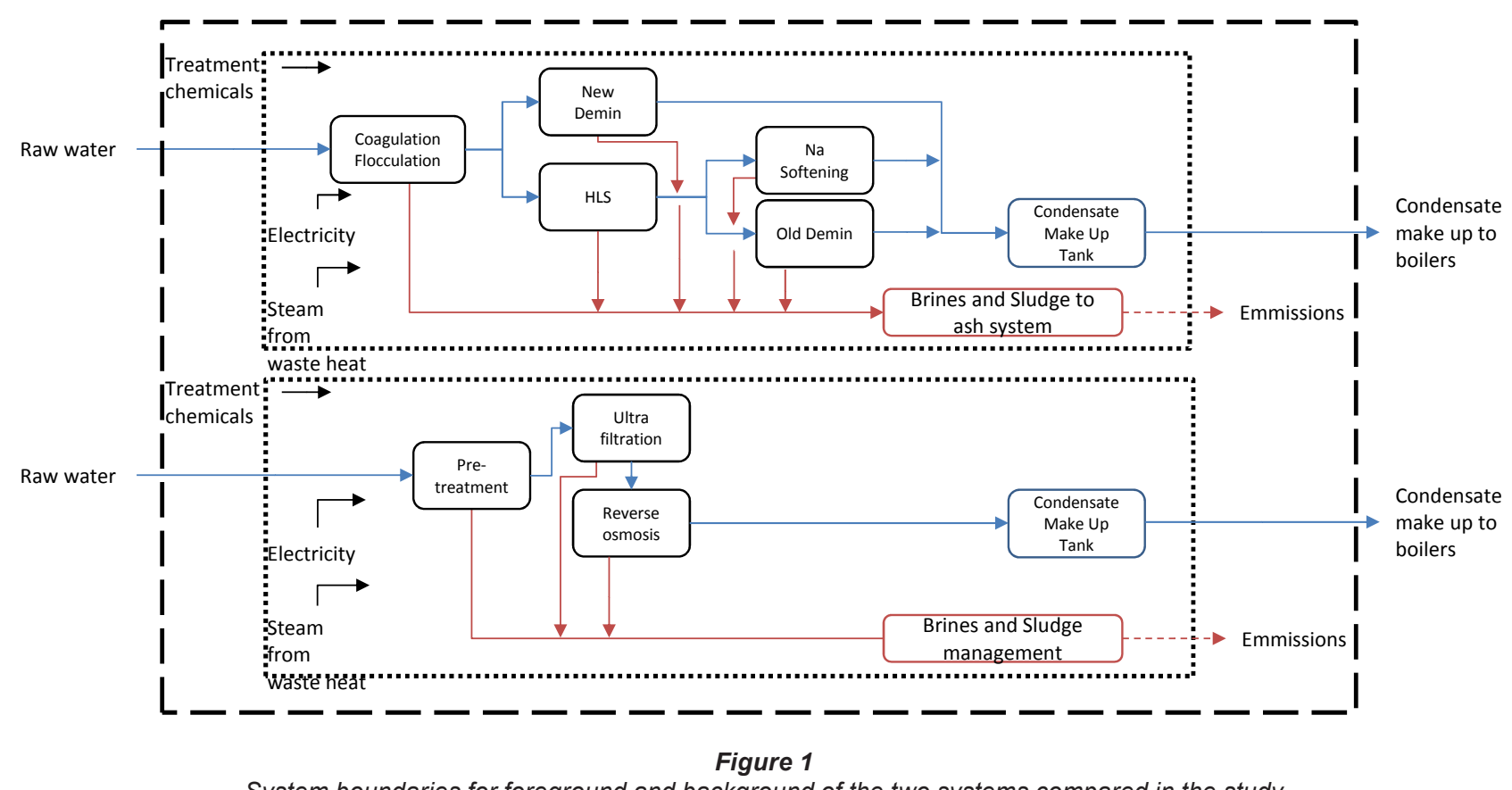

System boundaries for foreground and background of the two systems compared in the study 
Figure 2

IX/S system for $B F W$ preparation

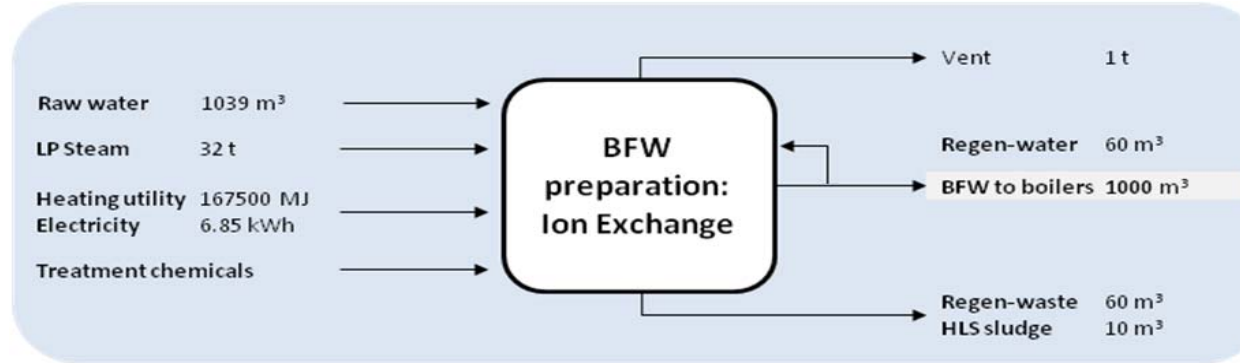

Figure 3

$R O$ system for BFW preparation

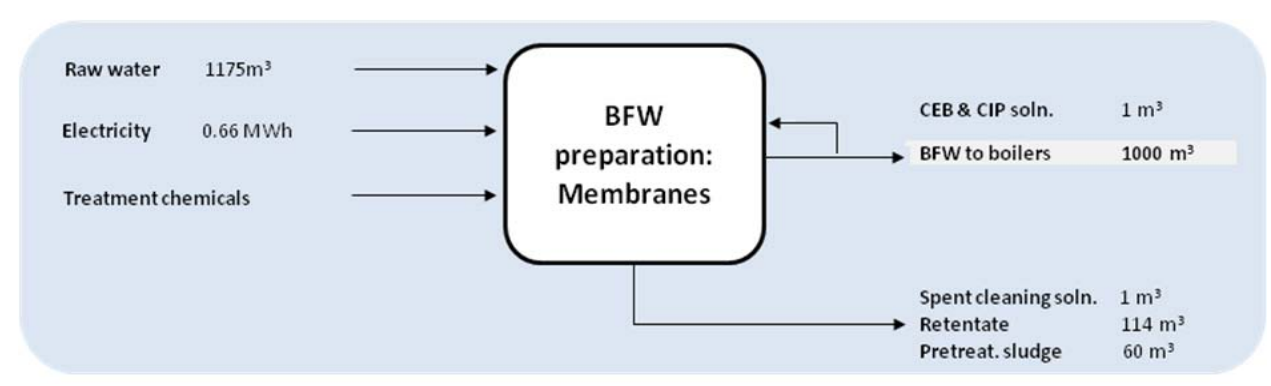

An alum coagulant, a treatment chemical shown in Fig. 2 , is dosed at $50 \mathrm{mg} / \ell$, or $50 \mathrm{~kg}$ for the production of $1 \mathrm{M} \ell$ of BFW by the system (estimated from Gagnon et al. (1997)). Treatment chemicals for HLS include lime and soda ash which are dosed as indicated by process data (Ras, 2011). The regeneration of ion exchange resins is described in Ras (2011) and the required volume of treatment chemicals is listed in Table 2.

\begin{tabular}{|l|l|}
\hline \multicolumn{2}{|c|}{$\begin{array}{c}\text { Table 2 } \\
\text { Dissolved raw water salts } \\
\text { and treatment chemicals feed } \\
\text { (for pretreatment and resin } \\
\text { regeneration) to IX/S process }\end{array}$} \\
\hline Salts feed (kg) & $\mathbf{1 0 4}$ \\
\hline Raw water salts & $\mathbf{6 4 4}$ \\
\hline Treatment chemicals & 109 \\
\hline $\mathrm{NaOH}^{\mathrm{NaOH}}$ & 198 \\
\hline $\mathrm{H}_{2} \mathrm{SO}_{4}$ & 182 \\
\hline $\mathrm{NaCl}$ & 50 \\
\hline $\mathrm{Alum}$ coagulant & 19 \\
\hline $\mathrm{MgO}$ & 67 \\
\hline $\mathrm{Ca}(\mathrm{OH})_{2}$ & 19 \\
\hline $\mathrm{Na}_{2} \mathrm{CO}_{3}$ & \\
\hline
\end{tabular}

Figure 3 shows that the water loss of the RO system (15\%) is due to the loss of water to pre-treatment sludge and RO retentate.

Feed water is dosed at $5 \mathrm{mg} / \ell$ with chlorine gas $(0.15 \mathrm{~kg} / \mathrm{M} \ell$ $\mathrm{BFW})$, and sodium bisulphate $\left(\mathrm{NaHSO}_{3}\right)(0.012 \mathrm{~kg} / \mathrm{M \ell} \mathrm{BFW})$ to inhibit bio-fouling and prevent membrane damage by free residual chlorine (Hydronautics, 2008). Acid is dosed at $20 \mathrm{mg} / \ell$ or $25.7 \mathrm{~kg} / \mathrm{M} \ell \mathrm{BFW}$ as an anti-scalant mechanism. Hydrochloric acid is preferred to sulphuric acid, as the latter can increase sulphate scaling potential (Tate, 2008). At a specific power consumption of $0.1-0.2 \mathrm{kWh} / \mathrm{m}^{3}$, the ultrafiltration (UF) unit requires $0.1-0.2 \mathrm{MWh}$ per $1 \mathrm{M} \ell$ product from the UF system (Wilf et al., 2007). It is proposed that a chemicallyenhanced backwash is performed daily with a cleaning solution of around $0.056 \mathrm{~m}^{3} / \mathrm{M} \ell \mathrm{BFW}$ produced by the system.
Treatment chemicals $\mathrm{NaOH}$ and $\mathrm{NaOCl}$ are dosed at $10 \mathrm{mg} / \ell$ which translates to $0.01 \mathrm{~kg}$ of each chemical per M $\mathrm{BFW}$ produced by the process. At a specific power consumption of around $0.4-0.5 \mathrm{kWh} / \mathrm{m}^{3}$, the RO unit requires 0.4 to $0.5 \mathrm{MWh}$ per $1 \mathrm{M} \ell$ BFW produced by the system (Ras, 2011; Wilf et al., 2007; Harding, 2008). A biannual membrane restoration procedure requires cleaning with high and low $\mathrm{pH}$ treatments of $2 \% \mathrm{NaOH}$ and $2 \%$ citric acid respectively (Ras, 2011). The treatment chemicals required by the RO system are summarised in Table 3.

\begin{tabular}{|l|l|}
\hline \multicolumn{2}{|c|}{$\begin{array}{c}\text { Table 3 } \\
\text { Dissolved raw water salts and } \\
\text { treatment chemicals feed } \\
\text { (for pre-treatment and membrane } \\
\text { restoration) to RO process }\end{array}$} \\
\hline Salts feed (kg) & $\mathbf{1 1 7}$ \\
\hline Raw water salts & $\mathbf{2 6 . 5}$ \\
\hline Treatment chemicals & 25.7 \\
\hline $\mathrm{HCl}$ & 0.43 \\
\hline $\mathrm{NaHSO}$ & 0.02 \\
\hline $\mathrm{NaOH}_{3}$ & 0.22 \\
\hline $\mathrm{Citric} \mathrm{acid}$ & 0.15 \\
\hline $\mathrm{Cl}_{2}$ & \\
\hline
\end{tabular}

Resin regeneration, membrane performance restoration and the replacement of parts such as membranes and resins were included in the scope of the LCA (as described in Ras, 2011), but other maintenance activities, such as work on pumps and pipes, were excluded. Treatment chemicals, replacement resins and membranes were taken to be transported from the greater Johannesburg region to the Secunda area, a distance of approximately $150 \mathrm{~km}$. Impacts associated with the shipment of exotic materials (resins and membranes) acquired from international producers were considered to be negligible when compared to the rail and/or truck transportation required for final delivery to complex industries.

Included in the foreground system of the RO process is the production of electricity by the Tutuka power station for the 


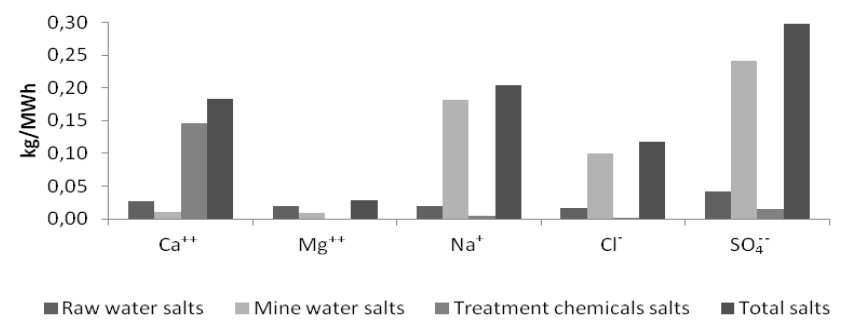

Figure 4

Footprint of problematic ions at Tutuka power station

high pressure pump unit of the RO process. Although marginal data should be used to populate the foreground systems of the consequential LCA, the choice of Tutuka data was made in order to demonstratively evaluate burden-shifting of salts at the level of the complex. The salts footprint of the power station is made up of ions contained in raw water, mine-water (which supplements raw water) and treatment chemicals, as presented in Fig. 4. Data for mine-water ions were calculated from the mine feedwater quality and quantity desalinated as provided by Buhrmann et al. (1999). Raw water ions were estimated from raw water quality data and the specific raw water consumption reported for Eskom at 2000 levels (Eskom, 2000), while treatment chemical salts were approximated for the water treatment operated at the power station (Pather, 2004; Ras, 2011).

Poor air quality in the Secunda complex results most notably from the emission of coal combustion gases and leads to several secondary effects such as climate change, soil effects and impaired human health. Eskom's emissions of $\mathrm{SO}_{2}, \mathrm{NO}_{x}$, $\mathrm{CO}_{2}$ and particulate matter are greater than those of electricity producers reflected in the EconInvent database, thus data for the life cycle inventories relating to the use of electricity were adjusted following Harding (2008) and Von Blottnitz (2006).

Two significant assumptions were made. Firstly, it was assumed that ample waste heat is available for the softening units of the IX/S system and that this aspect of the current water preparation system therefore carries zero environmental burden. Secondly, based on the Integrated Resources Plan for 2010-2030 (IRP, 2011) it was assumed that marginal power capacity in South Africa is coal-based and not derived from renewables.

\section{Life cycle impact assessment results}

Figure 5 shows a comparison of relative environmental performance for the production of BFW from the two desalination technologies under study, as modelled in SimaPro.

The life cycle inventories of the two water treatment technologies (previous section) were modelled in LCA software SimaPro v7.3 to evaluate the environmental effects relative to the impact assessment method chosen for the study (CML 2 baseline 2000 V2.04). The software performed classification and characterisation. During classification, inventory items are allocated to the impact categories they correspond to by the definition of the impact assessment method. During characterisation, characterisation factors specific to the impact assessment method are applied to these inventory items in order to convert them into the same unit which may be added up to yield a total contribution of inventory items corresponding to a particular impact category. This is conducted for each of the impact categories and the results are illustrated alongside each other on a dimensionless basis for simple comparison. Table 4

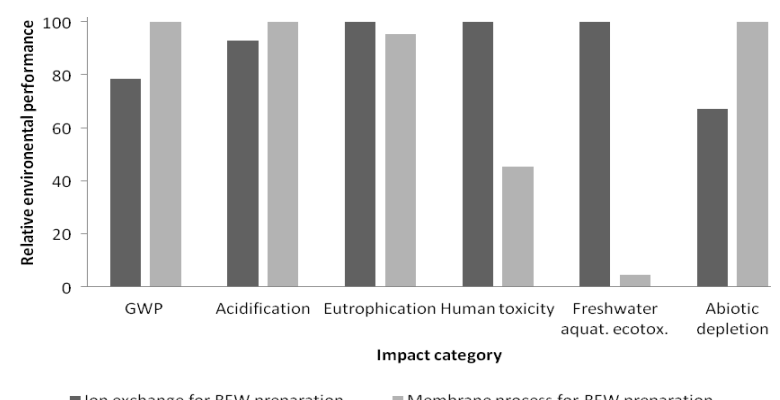

Figure 5

Comparison of characterisation results for the production of $1 \mathrm{M \ell} B F W$ by the two technologies under study

provides the process contributions of the two technologies in the units corresponding to the impact categories.

\begin{tabular}{|c|c|c|}
\hline \multicolumn{3}{|c|}{$\begin{array}{c}\text { Table } 4 \\
\text { Process contributions of the alternative water treatment } \\
\text { technologies relative to a selection of the impact } \\
\text { categories for CML } 2 \text { baseline } 2004\end{array}$} \\
\hline & $\mathrm{IX} / \mathrm{S}$ & RO \\
\hline \multicolumn{3}{|l|}{ GWP (kg CO ${ }_{2}$ eq/Me BFW) } \\
\hline Hard coal burned in power plant & 344 & 639 \\
\hline Quicklime & 51 & 0.25 \\
\hline Transport, lorry & 23 & 1.1 \\
\hline Magnesium oxide & 19 & - \\
\hline Hard coal & 14 & 26 \\
\hline Other processes & 83 & 15 \\
\hline Total GWP & 534 & 681 \\
\hline \multicolumn{3}{|l|}{ Acidification (kg SO ${ }_{2}$ eq/Me BFW) } \\
\hline Hard coal burned in power plant & 4.0 & 7.5 \\
\hline Secondary sulphur at refinery & 1.8 & 0.0075 \\
\hline Sulphuric acid, at plant, liquid & 1.7 & 0.0070 \\
\hline Other processes & 0.58 & 0.28 \\
\hline Total acidification & 8.2 & 7.8 \\
\hline \multicolumn{3}{|l|}{ Human toxicity (kg 1,4 -BD eq/Me BFW) } \\
\hline Disposal, red mud from bauxite digestion & 9.6 & 0.1 \\
\hline Hard coal burned in power plant & 7.8 & 14 \\
\hline Monoethanolamine & 4.4 & 3.4E-05 \\
\hline Other processes & 29 & 8.7 \\
\hline Total human toxicity & 51 & 23 \\
\hline \multicolumn{3}{|l|}{ Abiotic depletion (kg Sb eq/Me BFW) } \\
\hline Hard coal at mine & 3.1 & 5.7 \\
\hline Crude oil production, onshore & 0.15 & 0.0074 \\
\hline Other processes & 0.67 & 0.093 \\
\hline Total abiotic depletion & 3.9 & 5.8 \\
\hline \multicolumn{3}{|l|}{ Eutrophication(kg PO${ }_{4}{ }^{2-}$ eq/Me BFW) } \\
\hline Hard coal burned in power plant & 0.15 & 0.27 \\
\hline Sodium carbonate & 0.029 & - \\
\hline Blasting & 0.025 & 0.044 \\
\hline Other processes & 0.10 & 0.016 \\
\hline Total eutrophication & 0.30 & 0.33 \\
\hline \multicolumn{3}{|c|}{ Freshwater aquatic ecotoxicity (kg 1,4-BD eq/Me BFW) } \\
\hline Disposal, red mud from bauxite digestion & 22.4 & 0.28 \\
\hline Magnesium oxide & 9.6 & - \\
\hline Disposal, hard coal ash & 0.26 & 0.42 \\
\hline Other processes & 5.1 & 0.99 \\
\hline Total FAE & 37 & 1.7 \\
\hline
\end{tabular}




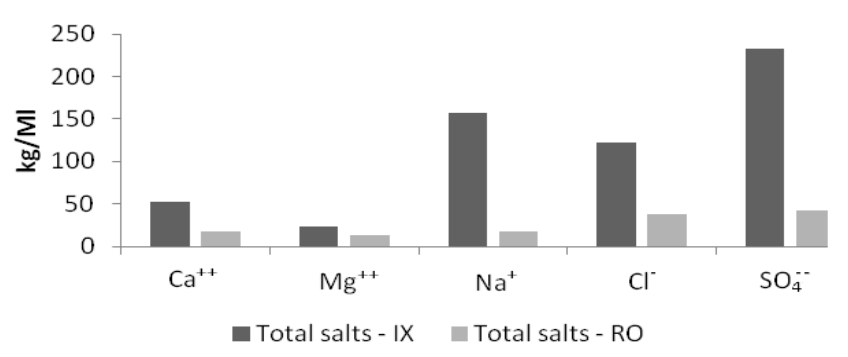

Figure 6

Comparison of the salts footprints of IX/S and RO technologies

Emissions contributing to greenhouse gases (GHGs) for RO are greater than those of the IX process by a factor of about 1.3. The GHG emissions associated with thermally inefficient electricity generation account for the only significant source (94\%) of GHG emissions for the RO intervention while the major component of the IX process' contribution to GWP is indirectly attributed to the use of sodium hydroxide in demineralisation units for resin regeneration. Greenhouse gas emissions associated with electricity input for electrolysis of $\mathrm{NaCl}$ brine to produce $\mathrm{NaOH}$ account for around $64 \%$ of the total GWP impact of this desalination process $\left(344 \mathrm{~kg} \mathrm{CO}_{2}\right.$ equivalent out of a total of $534 \mathrm{~kg} \mathrm{CO}_{2}$ equivalent per $\mathrm{M} \ell \mathrm{BFW}$ produced). Hot lime softening treatment chemicals, lime and magnesium oxide, respectively contribute $10 \%$ and $3 \%$ of the total GWP impact of the IX/S process. GHG-emitting processes associated with the production of lime include energy-intensive crushing of limestone, carbon dioxide-releasing calcination and electricity for pre-heating of heavy fuel oil used in heavy machinery.

The IX/S process performs relatively worse than the RO system for toxicity effects. For the RO process, $62 \%$ of total emissions contributing to 'human toxicity' are accounted for by the collection of processes that culminate in the coalbased generation of electricity to power high-pressure pumps. Chemical production processes contribute to the environmental burdens of the IX/S process and, in particular, the IX/S option fares worse than the RO option in terms of toxic emissions. Aluminium sulphate coagulant used in pre-treatment of the IX/S system results in adverse impacts on human toxicity and freshwater aquatic ecotoxicity.

The salts analysis summarised in Fig. 6 indicates that the IX/S process performs worse for the salinisation impact category, which was modelled at the inventory level.

Despite the desalination of hyper-saline mine water at the power station on which the RO intervention relies for its power supply, this method of BFW production would introduce almost 5 times fewer salty cations and 4.4 times fewer salty anions into problematic indefinite storage in the complex, thus reducing the salinity problem in the complex significantly.

\section{Discussion}

A central interest of this work was in environmental sustainability problems relating to salts and water. An important finding in this regard was that the $\mathrm{RO}$ intervention would reduce storage of problematic salts 4.4 to 5 fold, without shifting a salt burden to another industrial operation, despite a salt burden inherent to the electricity used to pressurise the RO system. The electricity was modelled using a 'worst case', non-typical scenario for electricity with regard to salts footprint: the power station supplying electrical energy desalinates highly salty water from a nearby mine.

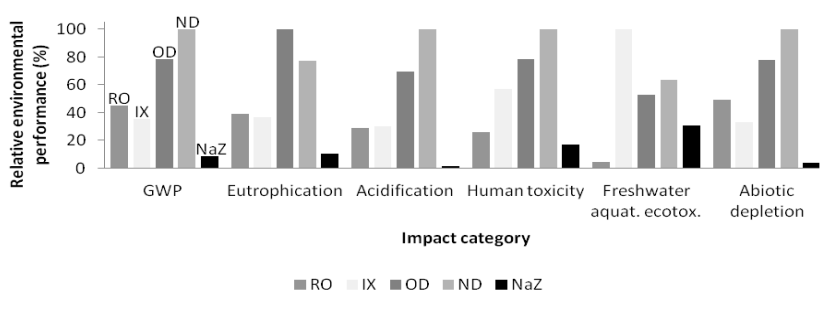

Figure 7

Environmental performance of different ion exchange technologies in relation to $R O$ and IX/S

For all other impact categories used in the study, the environmental performance of the RO system is dominated by effects relating to the use of electricity from a thermal power plant. If less polluting electricity could be sourced, the environmental performance of both technology life cycles would improve, but more so in the RO system.

Aluminium sulphate, a pre-treatment chemical in the IX/S system, represents a specific instance of burden shifting. Red mud is a problematic solid waste by-product in the production of aluminium sulphate which is disposed of in landfills, with the potential for leakage or spillage of a range of heavy metal contaminants from the landfill facility into groundwater and river systems (Tan and Khoo, 2003). Toxic metals such as arsenic, cadmium, chromium IV, antimony, cobalt, nickel, vanadium and selenium are thus potentially available for direct ingestion by aquatic ecosystems and direct or indirect exposure of human populations. Thus the IX/S process results in burden shifting to geographies outside of the borders of the Secunda complex.

During commercial operation of the IX/S system, operators change the ratio of $\mathrm{NaZ}$ to OD\&ND product according to downstream requirements. Figure 7 compares environmental performances of the various IX/S technologies (OD, ND, NaZ) which operate in conjunction with one another as shown in Fig. 1. The results in Fig. 7 were obtained similarly to those in Fig. 5, with SimaPro v7.3 for impact assessment (classification and characterisation).

The results in Fig. 7 indicate that the RO intervention becomes preferable from an environmental point of view for low NaZ to OD\&ND product ratios. For the production of $1 \mathrm{M \ell}$ of boiler feed water, ND and OD units individually have more detrimental overall effects on the environment compared to the RO process. The environmental impact of the combined IX/S system $(6 \%$ OD product, $23 \% \mathrm{ND}$ product, $71 \% \mathrm{NaZ}$ product by volume) is reduced by the low percentage of OD product (which has a larger impact compared to $\mathrm{RO}$ for $1 \mathrm{M} \ell$ produced) and a larger portion of less intensively treated, poorer quality $\mathrm{NaZ}$ product (which has a reduced impact compared to RO for $1 \mathrm{Ml}$ produced).

\section{Conclusion}

A comparative life cycle assessment was performed to determine the environmental performance of ion exchange relative to reverse osmosis for the treatment of raw water to boiler water. A significant finding from the LCA includes that, despite sourcing electricity from a power station which desalinates highly saline mine water, the RO intervention would strongly reduce salinisation risks in the studied system, without shifting of salts problems from one place to another. However, for impact categories relating to abiotic resource depletion and greenhouse gas emissions, the RO intervention is associated 
with an approximately $22 \%$ poorer environmental performance compared to IX system.

A variation analysis showed that, when the IX technologies (OD, ND and NaZ) were compared individually to RO, products from demineralisation units had significantly greater environmental burdens than RO. Given that the ratio of sodium softening to demineralisation unit product is changed according to downstream requirements, it may be generalised that RO technology becomes preferable from an environmental point of view for low sodium softening to demineralisation product ratios.

\section{Acknowledgements}

This research was made possible by generous funding received from the Minerals to Metals Group at the University of Cape Town. The authors gratefully acknowledge inputs from the reviewer, the Water Research Commission (Project K5/1833/3), Sasol, Eskom, Dave Rogers and Godfrey Mvuma at the CSIR.

\section{References}

BUHRMANN F, VAN DER WALT M, HANEKOM DJ and FINLAYSON F (1999) Treatment of industrial wastewater for reuse. Desalination 124 263-269.

BURGER AJ (2004) Mine water pollution and treatment technologies. Proc. Advances in Mineral Resources Management and Environmental Geotechnology, 7-9 June 2004, Hania, Greece.

ECONINVENT (2011) Database. URL: www.ecoinvent.org/database/ (Accessed October 2010).

ESKOM HOLDINGS LIMITED (2000) Eskom's Environmental Policy. Statistics Report. URL: http://www.eskom.co.za/annreport07/annreport07/info_sheets/impact.htm (Accessed October 2010).

GAGNON C, GRANDJEAN BPA and THIBAULT J (1997) Modelling coagulant dosage in a water treatment plant. Artif. Intell. Eng. 11 401-404.

HARDING K (2008) A Generic Approach to Environmental Assessment of Microbial Bioprocesses through Life Cycle Assessment. Ph.D. thesis, University of Cape Town, South Africa.

HYDRONAUTICS and NITTO DENKO (2008) Chemical Pretreatment for RO and NF. URL: www.membranes.com/docs/tab/ TAB111.pdf (Accessed October 2010).
DEPARTMENT OF ENERGY (2011) Integrated Resources Plan for 2010-2030. URL: www.doe-irp.co.za/content/IRP2010_2030 Final Report 20110325.pdf(Accessed March 2012).

PATHER V (2004) Eskom and Water. Proceedings of the 2004 Water Institute of Southern Africa (WISA) Biennial Conference, Cape Town, South Africa. URL: http://www.ewisa.co.za/literature/ files/260.pdf (Accessed October 2010).

RAS C, VON BLOTTNITZ H and ROGERS DEC (2010a) An assessment of the key factors that influence the environmental sustainability of a large inland industrial complex. Description of the environmental sustainability problem in the Secunda Complex and review of the literature on industrial ecology approaches and technologies. WRC Project No. K5/1833/3 Deliverable 5a, 19 March 2010. Water Research Commission, Pretoria.

RAS C, VON BLOTTNITZ H and ROGERS DEC (2010b) An assessment of the key factors that influence the environmental sustainability of a large inland industrial complex. Development and assessment of Cleaner Production options. WRC Project No. K5/1833/3, Deliverable 5b, 30 April 2010. Water Research Commission, Pretoria.

RAS C (2011) An Industrial Ecology Approach to Salt-Related Environmental Sustainability Issues in a Large Industrial Complex. M.Sc. Thesis, University of Cape Town, South Africa.

ROGERS DEC, MVUMA G, BRENT A, OELOFSE S and GODFREY L (2008) Draft final inception report for WRC Project No. K5/1833/3, 31 October 2008. An assessment of the key factors that influence the environmental sustainability of a large inland industrial complex. Water Research Commission, Pretoria.

ROUX PJD (2010) Personal communication, May 2010. Du-Toit Roux, Senior Process Engineer, Sasol Synthetic Fuels at Secunda. PO Box 5846, Johannesburg, South Africa.

TAN RBH and KHOO HH (2005) An LCA study of a primary aluminum supply chain. J. Clean. Prod. 13 607-618.

TATE J (2008) Industrial Reverse Osmosis Design. Water Cond. Purif. Mag. 50 (7) 3.

THE NATURAL STEP (2011) The Natural Step Framework. URL: www.naturalstep.org (Accessed October 2010).

VON BLOTTNITZ H (2006) A comparison of air emissions of thermal power plants in South Africa and 15 European countries. J. Energ. S. Afr. 17 (1) $72-81$.

WILF M, AWERBUCH L, BARTLES C, MICKLEY M, PEARCE G and VOUTCHKOV N (2007) The Guidebook to Membrane Desalination Technology. Balaban Desalination Publications. 